\title{
Association Between Sleep Quality and Falls: A Nationwide Population-Based Study from South Korea
}

\section{Sujin Lee' \\ Jae Ho Chung ${ }^{2}$ \\ Ji Hyun $\mathrm{Kim}^{3}$}

'Department of Neurology, International St. Mary's Hospital, Catholic Kwandong University College of Medicine, Incheon, Republic of Korea; ${ }^{2}$ Department of Internal Medicine, International St. Mary's Hospital, Catholic Kwandong University College of Medicine, Incheon, Republic of Korea; ${ }^{3}$ Department of Neurology, Korea University Guro Hospital, Korea University College of Medicine, Seoul, Republic of Korea
Correspondence: Ji Hyun Kim Department of Neurology, Korea University Guro Hospital, Korea University College of Medicine, Guro-dong Ro I48, Guro-gu, Seoul, 08308, Republic of Korea Tel +82 226263171

Email jhkim.merrf@gmail.com
Purpose: There are few large studies evaluating the association between sleep quality and the risk of falls. We aimed to determine the independent effect of poor sleep quality on an increased risk of falls using a large-sample dataset.

Methods: We conducted a retrospective, cross-sectional study using population-based data from the 2018 Korean Community Health Survey on 201,700 participants. Sociodemographic, mental health-related, and physical health-related variables as well as sleep quality evaluated by the Pittsburgh Sleep Quality Index (PSQI) were compared between 2499 fallers who have experienced at least one fall during the past 12 months and 199,201 non-fallers. Multivariable logistic regression was performed to identify sleep quality variables significantly associated with an increased risk of falls.

Results: Fallers had poorer sleep quality (PSQI score $>5$ ) and higher scores for global PSQI and individual PSQI components than did non-fallers (all $\mathrm{p}<0.001$ ). Multivariable logistic regression adjusted for potential confounders including socioeconomic, physical healthrelated, and mental health-related variables showed that an increased risk of falls was associated with poor sleep quality (odds ratio [OR] 1.30, 95\% confidence interval [CI] 1.19-1.42). Subgroup analyses by age revealed that poor sleep quality was significantly associated with an increased risk of falls in all three adult age groups. Multivariable logistic regression using the seven PSQI components revealed that an increased risk of falls was associated with short sleep duration (OR 1.14, CI 1.09-1.20), increased sleep disturbances (OR 1.30, CI 1.16-1.46), and increased daytime dysfunctions (OR 1.21, CI 1.08-1.13).

Conclusion: Poor sleep quality caused by short sleep duration may be a principal risk factor of falls in adult populations. Increased sleep disturbances and daytime dysfunctions may also contribute to an increased risk of falls. Our results have clinical and public health perspectives that increasing sleep duration and reducing daytime dysfunctions and sleep disturbances could mitigate unintentional falls.

Keywords: falls, sleep quality, Pittsburgh sleep quality index

\section{Introduction}

Falls pose a global public health concern and are a leading cause of both fatal and non-fatal unintentional injuries, deaths, and premature nursing home placement, especially in the older adult population. ${ }^{1-4}$ Approximately one-third of communitydwelling older adults and more than half of those living in nursing homes fall every year, and about half of those fallers fall repetitively. ${ }^{5,6}$ Both the incidence and severity of falls increase with age and increased disability and functional impairment. $^{6,7}$ The high incidence, long-term consequences, and medical costs 
associated with both fatal and non-fatal fall-related injuries place a significant burden on the national health-care system. ${ }^{8,9}$

Factors known to increase the risk of falls include older age, obesity, osteoporosis, cognitive impairment and dementia, Parkinson's disease, history of stroke, and alcohol consumption. $^{10-13}$ Various sleep problems such as insomnia, ${ }^{14,15}$ insufficient sleep, ${ }^{13,16}$ increased sleep fragmentation, ${ }^{16}$ and excessive daytime sleepiness, ${ }^{17}$ could also be responsible for the increased risk of falls. Notably, former studies consistently showed that short sleep duration is a principal risk factor of falls and fall-related injuries in older adults ${ }^{13,16,18,19}$ and adolescents. ${ }^{20-22}$ Poor sleep quality resulting from diverse sleep disturbances may lead to excessive daytime sleepiness, daytime psychomotor impairment, and decreased attention and cognitive performance, ${ }^{23-25}$ thereby eventually resulting in an increased risk of falls and fall-related injuries. ${ }^{26,27}$

Although sleep quality has been widely utilized in the fields of sleep science and medicine, this term lacks a definitional consensus. ${ }^{28,29}$ Sleep quality is generally referred to as a constellation of sleep measures including sleep latency and duration, sleep efficiency, sleep fragmentation, and disruptive nocturnal events such as apneas, abnormal behaviors, or arousals. ${ }^{28}$ Good sleep quality is a well-known indicator of mental health, physical health, and overall vitality, and efforts have recently been made on providing scientifically sound recommendations with respect to indicators of good sleep quality. ${ }^{30}$ The Pittsburgh Sleep Quality Index (PSQI) is the most extensively used self-administered questionnaire for assessment of sleep quality and patterns during the past month. ${ }^{31}$ It provides a reliable and standardized measure to discriminate good sleepers from poor sleepers, and has high internal consistency and strong test-retest reliability and validity. ${ }^{32}$ Notwithstanding the increased recognition of poor sleep quality as an important risk factor for falls, very few studies have investigated this association using population-representative samples. ${ }^{33}$ In this population-based study using a large-sample dataset, we investigated the effect of sleep quality and disturbances measured by the PSQI on the risk of falls among a cohort of adults aged $\geq 19$ years. We predicted that poor sleep quality may be associated with an increased risk of falls, independent of confounders such as socioeconomic, physical health-related, and mental healthrelated variables.

\section{Materials and Methods}

Study Population and Data

For this study, we acquired data from the 2018 Korean Community Health Survey (KCHS), a nationwide crosssectional survey carried out by the Korea Centers for Disease Control and Prevention. This community-based health interview survey is conducted annually since 2008 by 254 community health centers from the 17 metropolitan cities and provinces, 35 community colleges, and 1500 interviewers, in order to explore the patterns of personal lifestyle, mental and physical health-related behaviors, and disease prevalence and morbidity in adults aged $\geq 19$ years (the minimum age for adult in South Korea). ${ }^{34}$ The sample size for each of the 254 community units is 900 participants, and the expected number of respondents in this survey is 228,600 . The KCHS employed a two-stage sampling process to ensure that the sample units are representative of the general population. ${ }^{35}$ The first stage involves selection of a sample area (tong/ban/ri) as a primary sample unit according to the number of households using a probability proportional to size sampling technique. The second stage of sampling process includes selection of sample households in each sample area using systematic sampling methods. To ensure the samples to be statistically representative of the general population, the survey data were weighted by reference to the sampling design.

Exclusion criteria were the following: (1) uninhabitable areas owing to redevelopment or reconstruction; (2) households in the nonresidential areas (eg, business district, industrial complex); (3) residences for specific groups (eg, lepers colony, dormitory, religious communities); and (4) households where the interviewer could not contact the family members after visiting the household more than three times. Data were collected by technicians trained in conducting computer-assisted in-person interviews. Among a total of 228,340 participants in the $2018 \mathrm{KCHS}, 26,640$ were excluded because they did not fill out the questionnaire variables listed in Tables 1 and 2. Accordingly, 201,700 participants without missing variables were finally selected for the statistical analysis in this study.

The KCHS data are publicly available, and all data are completely anonymized before its release. This study was exempted from the need for an Institutional Review Board review since it did not correspond to research on human participants, according to Article 2.2 of the Enforcement Rule of Bioethics and Safety Act in Korea. All procedures of the survey were conducted in accordance with the 
Table I Baseline Characteristics of the Fallers and Non-Fallers

\begin{tabular}{|c|c|c|c|}
\hline & $\begin{array}{l}\text { Fallers } \\
(n=2499)\end{array}$ & $\begin{array}{l}\text { Non-Fallers } \\
(n=199,201)\end{array}$ & p-value \\
\hline Age (y) & $59.6 \pm 17.5$ & $53.1 \pm 17.0$ & $<0.001$ \\
\hline \multicolumn{4}{|l|}{ Sex } \\
\hline Male & $908(36.3)$ & $93,059(46.7)$ & $<0.001$ \\
\hline Female & $1591(63.7)$ & $106,142(53.3)$ & \\
\hline Body mass index $\left(\mathrm{kg} / \mathrm{m}^{2}\right)$ & $23.7 \pm 3.5$ & $23.7 \pm 3.4$ & 0.897 \\
\hline \multicolumn{4}{|l|}{ Residence area } \\
\hline Urban & $1367(54.7)$ & $117,460(59.0)$ & $<0.001$ \\
\hline Rural & $1132(45.3)$ & $81,741(41.0)$ & \\
\hline Education & & & $<0.001$ \\
\hline Elementary school or lower & $899(36.0)$ & 40,65I (20.4) & \\
\hline Middle school & $373(14.9)$ & $23,069(11.6)$ & \\
\hline High school & $597(23.9)$ & $59,688(30.0)$ & \\
\hline College or higher & $630(25.2)$ & $75,793(38.0)$ & \\
\hline Marital status & & & $<0.001$ \\
\hline Married (living with spouse) & $1529(61.2)$ & 137,046 (68.8) & \\
\hline $\begin{array}{l}\text { Living alone (never married, } \\
\text { separated, divorced, widowed) }\end{array}$ & $970(38.8)$ & $62,155(31.2)$ & \\
\hline Employment status & & & $<0.001$ \\
\hline Employed & $1276(51.1)$ & $126,565(63.5)$ & \\
\hline Unemployed & $1223(48.9)$ & $72,636(36.5)$ & \\
\hline Household income & & & $<0.001$ \\
\hline Low & $1000(40.0)$ & $52,147(26.2)$ & \\
\hline Middle low & $693(27.7)$ & $56,522(28.4)$ & \\
\hline Middle high & $490(19.6)$ & $55,917(28.1)$ & \\
\hline High & $316(12.6)$ & $34,615(17.4)$ & \\
\hline Smoking & & & 0.004 \\
\hline Current smoker & $399(16.0)$ & $35,925(18.0)$ & \\
\hline Non-smoker, ex-smoker & $2100(84.0)$ & $163,276(82.0)$ & \\
\hline Risky drinker & & & $<0.001$ \\
\hline Yes & $57 \mid(22.8)$ & $55,618(27.9)$ & \\
\hline No & $1928(77.2)$ & 143,583 (72.1) & \\
\hline Regular exercise & & & $<0.001$ \\
\hline Yes & $1016(40.7)$ & $90,47 \mid(45.4)$ & \\
\hline No & $1483(59.3)$ & $108,730(54.6)$ & \\
\hline Hypertension & & & $<0.001$ \\
\hline Yes & $900(36.0)$ & $53,032(26.6)$ & \\
\hline No & $1599(64.0)$ & $146,169(73.4)$ & \\
\hline Diabetes mellitus & & & $<0.001$ \\
\hline Yes & $384(15.4)$ & $21,154(10.6)$ & \\
\hline No & $2115(84.6)$ & 178,047 (89.4) & \\
\hline Subjective cognitive decline & & & $<0.001$ \\
\hline Yes & $681(27.3)$ & $34,860(17.5)$ & \\
\hline No & $1818(72.7)$ & $|64,34|(82.5)$ & \\
\hline Perceived stress & & & $<0.001$ \\
\hline Yes & $677(27.1)$ & $46,602(23.4)$ & \\
\hline No & $1822(72.9)$ & $152,599(76.6)$ & \\
\hline
\end{tabular}

(Continued)
Table I (Continued).

\begin{tabular}{|l|c|c|c|}
\hline & $\begin{array}{c}\text { Fallers } \\
(\mathbf{n}=\mathbf{2 4 9 9})\end{array}$ & $\begin{array}{c}\text { Non-Fallers } \\
(\mathbf{n}=\mathbf{1 9 9 , 2 0 1 )})\end{array}$ & p-value \\
\hline $\begin{array}{l}\text { Perceived health status } \\
\text { Good } \\
\text { Moderate } \\
\text { Bad }\end{array}$ & $\begin{array}{c}596(23.8) \\
1030(41.2)\end{array}$ & $\begin{array}{c}72,736(36.5) \\
90,015(45.2)\end{array}$ & $<0.001$ \\
\hline PHQ-9 global score & $873(34.9)$ & $36,450(18.3)$ & \\
\hline $\begin{array}{l}\text { Depression } \\
\text { Yes (PHQ9 score } \geq 10)\end{array}$ & $3.4 \pm 4.3$ & $2.1 \pm 3.1$ & $<0.001$ \\
\hline No (PHQ9 score 0-9) & $209(8.4)$ & $6709(3.4)$ & $<0.001$ \\
\hline
\end{tabular}

Note: Data are presented as number (percent) or mean \pm standard deviation. Abbreviation: PHQ-9, Patient Health Questionnaire-9.

ethical standards of the National Research Committee and the 1964 Helsinki Declaration and its later amendments.

\section{Measures}

\section{Assessment of Falls}

Falls were determined by asking the question: "Have you experienced at least one fall and slip over the last 12 months?" The responses were either yes or no.

\section{Assessment of Sleep Quality}

Sleep quality was assessed using the Korean version of the PSQI, which was validated with a high specificity and sensitivity. ${ }^{36}$ Specifically, the PSQI comprises 19 items regarding seven sleep components: subjective sleep quality, sleep latency, sleep duration, sleep efficiency, sleep disturbances, use of sleep medication, and daytime dysfunction. ${ }^{31}$ Each component was scored on a scale ranging from 0 to 3 . A global PSQI score for the assessment of overall sleep quality can be determined by adding all seven component scores, resulting in a final score ranging from 0 to 21 . A global PSQI score of 5 or below generally indicates good sleep, and a score of 6 or above indicates poor sleep. ${ }^{37,38}$ Both global score and seven component scores of the PSQI were used in the statistical analyses.

\section{Covariates}

Sociodemographic variables included sex, age, body mass index, residence area (urban or rural), education level (elementary school or lower, middle school, high school, or college or higher), marital status (living with spouse or living alone), employment status (employed or unemployed), and household income (low, middle-low, middle-high, or high). ${ }^{39-42}$ 
Table 2 Comparisons of the PSQI Scores Between Fallers and Non-Fallers

\begin{tabular}{|c|c|c|c|}
\hline & $\begin{array}{l}\text { Fallers } \\
(n=2499)\end{array}$ & $\begin{array}{l}\text { Non-Fallers } \\
(n=199,201)\end{array}$ & p-value \\
\hline PSQI global score & $5.8 \pm 3.4$ & $4.7 \pm 2.9$ & $<0.001$ \\
\hline Good sleep (PSQI $\leq 5$ ) & $1400(56.0)$ & 139,704 (70.1) & $<0.001$ \\
\hline Poor sleep (PSQI > 5) & $1099(44.0)$ & $59,497(29.9)$ & \\
\hline Sleep quality & & & $<0.001$ \\
\hline 0 : very good & $278(11.1)$ & $29,376(14.7)$ & \\
\hline I: fairly good & $1357(54.3)$ & $124,934(62.7)$ & \\
\hline 2: fairly bad & 705 (28.2) & $38,395(19.3)$ & \\
\hline 3: very bad & $159(6.4)$ & $6496(3.3)$ & \\
\hline Sleep latency (score) & & & $<0.001$ \\
\hline $0: 0$ & $926(37.1)$ & $91,978(46.2)$ & \\
\hline I: $1-2$ & $706(28.3)$ & $59,184(29.7)$ & \\
\hline $2: 3-4$ & 447 (17.9) & $27,061(13.6)$ & \\
\hline 3: 5-6 & $420(16.8)$ & $20,978(10.5)$ & \\
\hline Sleep duration (h) & & & $<0.001$ \\
\hline $0:>7$ & $463(18.5)$ & $35,400(17.8)$ & \\
\hline I: 6-7 & $1228(49.1)$ & | I3,708 (57.1) & \\
\hline 2: $5-6$ & $453(18.1)$ & $32,613(16.4)$ & \\
\hline $3:<5$ & $355(14.2)$ & $17,480(8.8)$ & \\
\hline Sleep efficiency (\%) & & & $<0.001$ \\
\hline $0: \geq 85$ & $2163(86.6)$ & $183,623(92.2)$ & \\
\hline I: 75-84 & $234(9.4)$ & II,420 (5.7) & \\
\hline 2: $65-74$ & $66(2.5)$ & $2589(1.3)$ & \\
\hline $3: \leq 65$ & $36(1.4)$ & $1569(0.8)$ & \\
\hline Sleep disturbance (score) & & & $<0.001$ \\
\hline $0: 0$ & $227(9.1)$ & $35,458(17.8)$ & \\
\hline I: I-9 & $1661(66.5)$ & 138,882 (69.7) & \\
\hline 2: $10-18$ & $574(23.0)$ & $23,959(12.0)$ & \\
\hline 3: 19-27 & $37(1.5)$ & $902(0.5)$ & \\
\hline Use of sleeping medication & & & $<0.001$ \\
\hline 0 : not during the past month & $2318(92.8)$ & $191,273(96.0)$ & \\
\hline I: less than once a week & $46(1.8)$ & $2112(1.1)$ & \\
\hline 2: once or twice a week & $38(1.5)$ & $1633(0.8)$ & \\
\hline 3: three or more times a week & $97(3.9)$ & $4183(2.1)$ & \\
\hline Daytime dysfunction & & & $<0.001$ \\
\hline 0 : very good & $1550(62.0)$ & $136,814(68.7)$ & \\
\hline I: fairly good & $547(21.9)$ & $40,672(20.4)$ & \\
\hline 2: fairly bad & $323(12.9)$ & $18,238(9.2)$ & \\
\hline 3: very bad & $79(3.2)$ & $3477(1.7)$ & \\
\hline
\end{tabular}

Note: Data are presented as number (percent) or mean \pm standard deviation. Abbreviation: PSQI, Pittsburgh Sleep Quality Index.

Physical health-related variables included risky drinking (12 or more drinking episodes in which five or more alcoholic glasses were consumed during the last year) ${ }^{43}$ smoking status (current smoker or non-smoker/ex-smoker), regular exercise (at least $30 \mathrm{~min}$ of walking for at least 5 days per week), ${ }^{44}$ and presence of hypertension and diabetes mellitus. ${ }^{42,45}$
Mental health-related variables included perceived stress, perceived health status, subjective cognitive decline (SCD), and depression. ${ }^{40,41,46}$ Perceived stress was assessed by asking the following question: "How stressed do you feel in your daily life?" The responses were categorized as yes (severe or very severe) or no (rare or mild). Perceived health status was assessed by asking the following question, "How do you rate your health status in general?" The responses were categorized as good (very good or good), moderate, or bad (bad or very bad). According to the cognitive decline module of the Behavioral Risk Factor Surveillance System, ${ }^{47}$ SCD was determined by asking the single question, "Have you experienced frequent or worsening of memory loss or confusion during the last year?" The responses were either yes or no. Depressive symptoms were evaluated by the Patient Health Questionnaire-9 (PHQ-9), a widely adopted scale in population-based studies. ${ }^{48}$ The Korean version of the PHQ-9 used in this survey was validated previously. ${ }^{49}$ Nine items were measured to evaluate depressive symptoms during the past two weeks and were scored on a scale ranging from 0 to $3(0=$ none, $1=$ several days, $2=$ more than 7 days, $3=$ nearly every day). A global PHQ-9 score of $\geq 10$ indicates the presence of depression.

\section{Statistics}

Descriptive statistics illustrated the baseline characteristics of the study population. Sociodemographic, physical health-related, and mental health-related variables as well as sleep quality measures (PSQI scores) were compared between fallers and non-fallers using the Student's $t$-test, chi-square test, or Fisher's exact test, where appropriate.

Multivariable logistic regression was performed to determine the effects of overall sleep quality (ie, good vs poor sleep) on falls. Model 1 was adjusted for sex, age, and body mass index. Model 2 was adjusted for Model 1 variables and socioeconomic variables (residence area, education level, marital status, employment status, and household income). Model 3 was adjusted for Model 2 variables and physical health-related variables (risky drinking, smoking, regular exercise, hypertension, and diabetes mellitus) and mental health-related variables (perceived status of health, perceived level of stress, SCD, and depression). In addition, multivariable logistic regression using the seven PSQI components was carried out to determine which component factor is more closely associated with an increased risk of falls. For statistical 
analysis, each component score was categorized as good/ less (0-1) and bad/more (2-3).

Given that the risk factor of falls and the effect of sleep quality on falls may be different according to age groups, subgroup analyses using multivariable logistic regression were further performed for three adult age groups: young adults aged 19-39 years, middle-aged adults aged 40-59 years, and older adults aged $\geq 60$ years. Results were expressed as adjusted odds ratios (ORs) and 95\% confidence intervals (CIs). A p $<0.05$ indicates statistical significance in all tests. Statistical analyses were conducted using the Statistical Package for Social Sciences (version 25.0; IBM, Armonk, NY).

\section{Results}

The baseline characteristics of 2499 fallers and 199,201 nonfallers are presented in Table 1. Fallers were more likely to be female, older, living alone, unemployed, living in rural areas, and to have lower levels of household income and education than were non-fallers (all $\mathrm{p}<0.001$ ). Current smokers $(p=0.004)$, risky drinkers $(p<0.001)$, and regular exercisers $(p<0.001)$ were more frequently observed in non-fallers than in fallers. Fallers were found to have higher perceived stress, poorer perceived health status, and higher prevalence of hypertension, diabetes mellitus, SCD, and depression than were non-fallers (all $\mathrm{p}<0.001$ ).

Comparisons of the global PSQI score and each component score between the groups are summarized in Table 2. The global PSQI score was higher in fallers than in non-fallers $(5.8 \pm 3.4$ vs $4.7 \pm 2.9$, p $<0.001)$. As expected, poor sleeper (PSQI score $>5$ ) was more prevalent in fallers than in non-fallers $(44.0 \%$ vs $29.9 \%$, $\mathrm{p}<0.001)$. The scores for all seven PSQI components were higher in fallers compared with non-fallers (all $\mathrm{p}<$ 0.001), indicating that fallers had poorer overall sleep quality than did non-fallers.

Table 3 shows the independent effect of sleep quality variables measured by the PSQI on the risk of falls after adjustment for sex, age, and body mass index (Model 1); Model 1 variables and socioeconomic variables (Model 2); and Model 2 variables and physical and mental healthrelated variables (Model 3). Compared to good sleep quality (reference), poor sleep quality (PSQI score $>5$ ) was significantly associated with an increased risk of falls (Model 1: OR 1.62, CI 1.49-1.76; Model 2: OR 1.53, CI 1.41-1.66; Model 3: OR 1.30, CI 1.19-1.42). No significant interactions were observed between the PSQI and the other covariates (all $\mathrm{p}>0.05$ ). The fully adjusted model
(Model 3) using the seven PSQI components confirmed that an increased risk of falls was significantly associated with short sleep duration (OR 1.14, CI 1.09-1.20), increased sleep disturbances (OR 1.30, CI 1.16-1.46), and increased daytime dysfunctions (OR 1.21, CI 1.08-1.13).

Table 4 summarizes the results of subgroup analyses by age. Fallers and poor sleepers (PSQI score $>5$ ) were more frequently observed in older adults than in young and middleaged adults (both $\mathrm{p}<0.001$ ). A statistically significant stepwise increase in the global PSQI score was found from young adults to older adults (one-way ANOVA followed by Bonferroni correction, all $\mathrm{p}<0.001)$. Compared to good sleep quality, poor sleep quality (PSQI score $>5$ ) was significantly associated with an increased risk of falls in all three age groups: young adults (Model 1: OR 1.42, CI 1.15-1.75; Model 2: OR 1.36, CI 1.10-1.67; Model 3: OR 1.29, CI 1.03-1.61), middle-aged adults (Model 1: OR 1.76, CI 1.51-2.05; Model 2: OR 1.64, CI 1.41-1.92; Model 3: OR 1.44, CI 1.22-1.71), and older adults (Model 1: OR 1.54, CI 1.39-1.72; Model 2: OR 1.49, CI 1.34-1.66; Model 3: OR 1.26, CI 1.13-1.42).

\section{Discussion}

In this study, we evaluated the association between the risk of falls and sleep quality measured by the PSQI among a cohort of adults aged $\geq 19$ years. The main finding is that overall poor sleep quality independently contributed to an increased risk of falls in adult populations even after adjustment for potential confounders, although the effect of poor sleep quality on the risk of falls was alleviated as more confounders were included in the statistical models. The results of subgroup analyses according to adult age groups were substantially identical to that of the whole adult population. This study also indicated that an increased risk of falls was significantly associated with several components of sleep quality including short sleep duration, increased sleep disturbances, and increased daytime dysfunctions.

Previous studies have investigated the association between the risk of falls and sleep-related variables. The majority of the studies have focused on sleep duration and found that short sleep duration escalates the incident falls and injuries in the older adult population. ${ }^{13,16,18,19}$ Older women who are sleeping $\leq 5 \mathrm{~h}$ exhibited a 1.8 -fold greater risk of falls relative to those sleeping 7-8 h. ${ }^{16}$ Likewise, adults who slept $<7.5 \mathrm{~h}$ had a 1.6-fold greater risk of injuries relative to those sleeping 7.5-8.5 h. ${ }^{18}$ However, this association was not replicated in others. ${ }^{50,51}$ 
Table 3 Results of Multivariable Logistic Regression Analysis Showing Associations Between the PSQI Scores and the Risk of Falls

\begin{tabular}{|c|c|c|c|c|c|c|}
\hline & \multicolumn{2}{|c|}{ Model I } & \multicolumn{2}{|c|}{ Model 2} & \multicolumn{2}{|c|}{ Model 3} \\
\hline & OR & $95 \% \mathrm{Cl}$ & OR & $95 \% \mathrm{Cl}$ & OR & $95 \% \mathrm{Cl}$ \\
\hline \multicolumn{7}{|l|}{ PSQI } \\
\hline Good sleep (PSQI $\leq 5$ ) & I & Reference & I & Reference & I & Reference \\
\hline Poor sleep (PSQI > 5) & 1.62 & $1.49-1.76$ & 1.53 & $1.41-1.66$ & 1.30 & I.19-1.42 \\
\hline \multicolumn{7}{|l|}{ Subjective sleep quality } \\
\hline $0-1$ & I & Reference & I & Reference & I & Reference \\
\hline $2-3$ & 1.25 & $1.13-1.39$ & 1.23 & $1.11-1.36$ & 1.11 & $1.00-1.23$ \\
\hline \multicolumn{7}{|l|}{ Sleep latency } \\
\hline $0-1$ & I & Reference & 1 & Reference & I & Reference \\
\hline $2-3$ & 1.09 & $0.99-1.21$ & 1.06 & $0.95-1.17$ & 1.04 & $0.94-1.15$ \\
\hline \multicolumn{7}{|l|}{ Sleep duration } \\
\hline $0-1$ & I & Reference & 1 & Reference & I & Reference \\
\hline $2-3$ & 1.22 & $1.16-1.28$ & 1.15 & $1.10-1.21$ & 1.14 & $1.09-1.20$ \\
\hline \multicolumn{7}{|l|}{ Sleep efficiency } \\
\hline $0-1$ & 1 & Reference & I & Reference & I & Reference \\
\hline $2-3$ & 1.07 & $0.87-1.33$ & 1.04 & $0.84-1.29$ & 1.01 & $0.8 I-1.26$ \\
\hline \multicolumn{7}{|l|}{ Sleep disturbance } \\
\hline $0-1$ & 1 & Reference & 1 & Reference & 1 & Reference \\
\hline $2-3$ & 1.47 & $1.32-1.64$ & 1.43 & $1.28-1.59$ & 1.30 & $1.16-1.46$ \\
\hline \multicolumn{7}{|c|}{ Use of sleeping medication } \\
\hline $0-1$ & I & Reference & 1 & Reference & 1 & Reference \\
\hline $2-3$ & 1.06 & $0.88-1.27$ & 1.02 & $0.85-1.23$ & 0.94 & $0.78-1.13$ \\
\hline \multicolumn{7}{|l|}{ Daytime dysfunction } \\
\hline $0-1$ & I & Reference & 1 & Reference & 1 & Reference \\
\hline $2-3$ & 1.32 & I.18-1.48 & 1.31 & I.17-I.47 & 1.21 & $1.08-1.13$ \\
\hline
\end{tabular}

Notes: Model I was adjusted for sex, age, and body mass index; Model 2 was adjusted for Model I variables and socioeconomic variables (residence area, education level, marital status, employment status, and household income); Model 3 was adjusted for Model 2 variables and physical health-related variables (risky drinking, smoking, regular exercise, hypertension, and diabetes mellitus) and mental health-related variables (perceived status of health, perceived level of stress, subjective cognitive decline, and depression).

Abbreviations: $\mathrm{Cl}$, confidence interval; OR, odds ratio; PSQI, Pittsburgh Sleep Quality Index.

Interestingly, a meta-analysis of epidemiological and observational studies suggested that not only short sleep duration but also long sleep duration may lead to an increased falls in the adult population. ${ }^{52}$ The incongruent results across the studies might be partly ascribed to differences in potential confounders incorporated in the statistics, including socioeconomic variables, comorbid psychiatric and medical disorders, and the use of psychotropic and hypnotic medications. Indeed, a variety of conditions have been linked to the risk of falls and injuries in the older adult population, including dementia, Parkinson's disease, stroke, depression, diabetes mellitus, rheumatic diseases, pain disorders, dizziness/vertigo, vision impairment, and the use of sedatives and antiepileptic drugs. ${ }^{40}$ Given a high probability of the aforementioned conditions occurring in older adults, it is bewildering to decide whether short sleep duration per se acts as an independent factor associated with the risk of falls. This association could be more clearly demonstrated by using an adolescent population, since they are in overall good health, and therefore presumed to be free from the conditions that potentially increase the incident falls in the older adult population. ${ }^{20-22}$ Adolescent athletes who slept $<8 \mathrm{~h}$ per night reported a 1.7-fold higher risk of sports injuries than those sleeping $\geq 8 \mathrm{~h}$ on average. ${ }^{20}$ In a recent populationbased study using a large sample size $(57,255$ adolescents aged $12-18$ years), short sleep duration $(\leq 6 \mathrm{~h})$ was associated with an increased risk of falls, whereas long sleep duration ( $\geq 9 \mathrm{~h}$ ) and longer weekend catch-up sleep contributed to a decreased risk of falls. ${ }^{22}$ This study strongly 
Table 4 Results of Subgroup Analyses by Age Showing Associations Between the PSQI Scores and the Risk of Falls

\begin{tabular}{|c|c|c|c|c|c|c|c|}
\hline & \multicolumn{2}{|c|}{ Young Adult $(n=48,466)$} & \multicolumn{2}{|c|}{ Middle-Aged Adult $(n=75,737)$} & \multicolumn{2}{|c|}{ Older Adult $(n=77,497)$} & p-value \\
\hline Age (range, y) & \multicolumn{2}{|c|}{$30.1 \pm 6.2(19-39)$} & \multicolumn{2}{|c|}{$50.2 \pm 5.8(40-59)$} & \multicolumn{2}{|c|}{$70.5 \pm 7.5(\geq 60)$} & $<0.001$ \\
\hline Male/female & \multicolumn{2}{|c|}{$23,148 / 25,318$} & \multicolumn{2}{|c|}{$35,032 / 40,705$} & \multicolumn{2}{|c|}{$35,787 / 41,710$} & $<0.001$ \\
\hline Fallers & \multicolumn{2}{|c|}{$397(0.8)$} & \multicolumn{2}{|c|}{$700(0.9)$} & \multicolumn{2}{|c|}{$1402(1.8)$} & $<0.001$ \\
\hline $\begin{array}{l}\text { PSQI global score } \\
\text { Good sleep (PSQI } \leq 5) \\
\text { Poor sleep (PSQI >5) }\end{array}$ & \multicolumn{2}{|c|}{$\begin{array}{c}4.4 \pm 2.7 \\
35,486(73.2) \\
12,980(26.8)\end{array}$} & \multicolumn{2}{|c|}{$\begin{array}{c}4.5 \pm 2.7 \\
55,575(73.4) \\
20,162(26.6)\end{array}$} & \multicolumn{2}{|c|}{$\begin{array}{c}5.2 \pm 3.1 \\
50,043(64.6) \\
27,454(35.4)\end{array}$} & $\begin{array}{l}<0.001 \\
<0.001\end{array}$ \\
\hline & OR & $95 \% \mathrm{Cl}$ & OR & $95 \% \mathrm{Cl}$ & OR & $95 \% \mathrm{Cl}$ & \\
\hline $\begin{array}{l}\text { Model I } \\
\text { Good sleep (PSQI } \leq 5) \\
\text { Poor sleep (PSQI >5) }\end{array}$ & $\begin{array}{c}1 \\
1.42\end{array}$ & $\begin{array}{l}\text { Reference } \\
\text { I.15-1.75 }\end{array}$ & $\begin{array}{c}1 \\
1.76\end{array}$ & $\begin{array}{l}\text { Reference } \\
1.5 \mathrm{I}-2.05\end{array}$ & $\begin{array}{c}1 \\
1.54\end{array}$ & $\begin{array}{l}\text { Reference } \\
1.39-1.72\end{array}$ & \\
\hline $\begin{array}{l}\text { Model } 2 \\
\text { Good sleep (PSQI } \leq 5) \\
\text { Poor sleep (PSQI >5) }\end{array}$ & $\begin{array}{c}1 \\
1.36\end{array}$ & $\begin{array}{l}\text { Reference } \\
\text { I.10-1.67 }\end{array}$ & $\begin{array}{c}1 \\
1.64\end{array}$ & $\begin{array}{l}\text { Reference } \\
1.4 \mid-1.92\end{array}$ & $\begin{array}{c}1 \\
1.49\end{array}$ & $\begin{array}{c}\text { Reference } \\
1.34-1.66\end{array}$ & \\
\hline $\begin{array}{l}\text { Model } 3 \\
\text { Good sleep (PSQI } \leq 5) \\
\text { Poor sleep (PSQI >5) }\end{array}$ & $\begin{array}{c}1 \\
1.29\end{array}$ & $\begin{array}{c}\text { Reference } \\
1.03-1.6 \mid\end{array}$ & $\begin{array}{c}1 \\
1.44\end{array}$ & $\begin{array}{c}\text { Reference } \\
|.22-| .7 \mid\end{array}$ & $\begin{array}{c}1 \\
1.26\end{array}$ & $\begin{array}{l}\text { Reference } \\
1.13-1.42\end{array}$ & \\
\hline
\end{tabular}

Notes: Data are presented as number (percent) or mean \pm standard deviation. Group comparisons were made using one-way ANOVA or chi-square test, where appropriate; Model I was adjusted for sex, age, and body mass index; Model 2 was adjusted for Model I variables and socioeconomic variables (residence area, education level, marital status, employment status, and household income); Model 3 was adjusted for Model 2 variables and physical health-related variables (risky drinking, smoking, regular exercise, hypertension, and diabetes mellitus) and mental health-related variables (perceived status of health, perceived level of stress, subjective cognitive decline, and depression). Abbreviations: $\mathrm{Cl}$, confidence interval; OR, odds ratio; PSQI, Pittsburgh Sleep Quality Index.

suggests that insufficient sleep is a key risk factor for falls, and that long sleep duration as well as weekend catch-up sleep exerts a protecting influence against falls. ${ }^{22}$ In our fully adjusted model using the seven PSQI components, short sleep duration (OR 1.14, CI 1.09-1.20) independently contributed to an increased risk of falls. Collectively, our results accord well with those of previous studies, pointing to the deleterious effect of short sleep duration on the risk of falls in adult populations.

The possible link between the risk of falls and sleep quality variables other than sleep duration has not been sufficiently studied. To our knowledge, there is one publicly available study that investigated the relationship between incident falls in older men and sleep disturbances using both objective (actigraphy) and subjective sleep measurements (PSQI and Epworth Sleepiness Scale). ${ }^{53}$ In multivariable-adjusted models, participants who reported excessive daytime sleepiness (Epworth Sleepiness Scale score $>10$ ) and slept $\leq 5 \mathrm{~h}$ as per actigraphic measurement were significantly associated with greater odds of experiencing recurrent falls than were their counterparts. The associations between recurrent falls and poor sleep quality (PSQI score $>5$ ) and self-reported short sleep time $(<5 \mathrm{~h})$ were also significant after minimal adjustment, but were no longer significant after further adjustment for multiple confounders. $^{53}$ In our study analyzing individual PSQI components, the risk of falls was associated with short sleep duration $(<6 \mathrm{~h})$, increased sleep disturbances (ie, difficulty falling asleep, sleep fragmentation, nocturia, sleep-disordered breathing, cold/hot feelings, bad dreams, and pain), and increased daytime dysfunctions (ie, excessive daytime sleepiness and difficulty concentrating), in line with the previous study findings. ${ }^{53}$ Taken together, the increased risk of falls could be linked not only to insufficient sleep due to short sleep duration, but also to increased sleep disturbances and daytime dysfunctions.

Although not thoroughly elucidated, plausible mechanisms linking poor sleep quality to falls have been proposed in prior studies. First, consequences of poor sleep quality including impaired daytime functioning, excessive daytime sleepiness, poor cognitive performance, and depressive symptoms have been reported to increase the incident falls and fall-related injuries. ${ }^{24,54-56}$ Second, sleep deprivation and fragmentation due to sleep disturbances cause poor physical functioning and balance/posture control, ${ }^{57-60}$ eventually leading to an increased incidence of falls in sleep-deprived 
persons. In addition, reductions in sleep duration and quality might be related to sarcopenia, ${ }^{61}$ a potential risk factor for injuries and falls, especially in older adults. ${ }^{62,63}$ Third, poor sleep quality and short sleep duration were related with increased cerebral white matter hyperintensities and stroke in older adults, ${ }^{64-66}$ which was established as a robust risk factor for incident falls. ${ }^{67}$ Last, short sleep duration may provoke a proinflammatory state by increasing levels of inflammatory cytokines including tumor necrosis factor alpha and interleukin- $6 .{ }^{68,69}$ This chronic inflammatory condition could cause diminished muscle mass and strength as well as reduced gait speed, leading to an increased incidence of falls. ${ }^{70,71}$

The strengths of this study may be the use of a population-based, large-sample dataset and the adoption of a sampling process representative of the general population. Furthermore, this survey offered information regarding a number of confounders related with falls, which allowed us to explore the independent effect of poor sleep quality on the risk of falls using multiple statistical adjustments. Our results need to be interpreted within the confines of at least five potential limitations. First, the causality between poor sleep quality and the risk of falls could not be established due to the cross-sectional design in this survey. Second, because all data were entirely collected via self-administered questionnaires, recall bias leading to the probability of under- or overreporting cannot be totally excluded. Furthermore, subjective measures for sleep (ie, PSQI scores) have shown weak or inconsistent correlations with objective measures (ie, actigraphy and polysomnography), ${ }^{72-74}$ thus, future studies adopting both types of sleep measures are required to corroborate our findings. Third, although the PSQI cutoff score of 5 is the most widely used in sleep medicine, there has been some debate as to whether this cutoff score could be an optimal threshold indicating good or poor sleep quality. Some authors suggested a higher threshold to substantially differentiate good sleepers from poor sleepers. ${ }^{75,76}$ Moreover, a recent study found a discrepancy between the PSQI scores on work-free days and workdays, suggesting the influences of chronotype and social jetlag on sleep quality. ${ }^{77}$ Fourth, dichotomous question for history of falls may limit assessment of clinical significance of falls such as place and number of falls, severity of falls, and associated morbidity. Moreover, sleep quality measured during the past one month is insufficient to be analyzed to assess the risk of falls that occurred during the past 12 months. Last, we did not investigate the use of fall risk-increasing drugs, such as analgesics, psychotropic drugs (antipsychotics, anxiolytics, antidepressants), cardiovascular drugs, and polypharmacy, ${ }^{78-80}$ which might affect the results.

\section{Conclusions}

Sleep deprivation has been strongly linked to falls, a leading cause of morbidity and mortality particularly in the older adult population. Our nationwide population-based study using the PSQI corroborates the previous finding that poor sleep quality caused by short sleep duration is a major risk factor of falls in adult populations. Furthermore, our findings imply that increased sleep disturbances and daytime dysfunctions independently contribute to the risk of falls. Our results have clinical and public health perspectives that increasing sleep duration and reducing daytime dysfunctions and sleep disturbances could mitigate unintentional falls and fall-related injuries. Further prospective longitudinal studies using both objective and subjective assessments of sleep quality on a large scale are required to confirm the detrimental influence of poor sleep quality on the risk of falls.

\section{Abbreviations}

PHQ-9, patient health questionnaire-9; PSQI, Pittsburgh sleep quality index; SCD, subjective cognitive decline.

\section{Data Sharing Statement}

The dataset used and analyzed in the current study is available from the corresponding author on reasonable request. Raw data are available on the Korea Community Health Survey website (https://chs.kdca.go.kr/chs/index.do).

\section{Acknowledgment}

The authors are grateful to all participants for their voluntary participation and compliance with the study protocol.

\section{Funding}

This work was supported by the National Research Foundation of Korea Grant funded by the Korean Government (Grant No. NRF-2018R1D1A1B07048207). The funder did not have any role in the study design, data collection, analysis and interpretation of data, or writing the manuscript.

\section{Disclosure}

All authors declare no potential conflicts of interest. 


\section{References}

1. Kannus P, Parkkari J, Koskinen S, et al. Fall-induced injuries and deaths among older adults. $J$ Am Med Assoc. 1999;281 (20):1895-1899. doi:10.1001/jama.281.20.1895

2. Rivara FP, Grossman DC, Cummings P. Injury prevention. First of two parts. $N$ Engl J Med. 1997;337(8):543-548. doi:10.1056/ NEJM199708213370807

3. DeGrauw X, Annest JL, Stevens JA, Xu LK, Coronado V. Unintentional injuries treated in hospital emergency departments among persons aged 65 years and older, United States, 2006-2011. J Safety Res. 2016;56:105-109. doi:10.1016/j.jsr.2015.11.002

4. Stevens JA, Ryan G, Kresnow M. Fatalities and injuries from falls among older adults United States, 1993-2003 and 2001-2005 (Reprinted from MMWR, vol 55, pg 1221-1224, 2006). J Am Med Assoc. 2007;297(1):32-33.

5. Tinetti ME, Speechley M. Prevention of falls among the elderly. New Engl J Med. 1989;320(16):1055-1059. doi:10.1056/NEJM198 904203201606

6. Rubenstein LZ, Josephson KR, Robbins AS. Falls in the nursing home. Ann Intern Med. 1994;121(6):442-451. doi:10.7326/00034819-121-6-199409150-00009

7. van Weel C, Vermeulen H, van den Bosch W. Falls, a community care perspective. Lancet. 1995;345(8964):1549-1551. doi:10.1016/ S0140-6736(95)91091-3

8. Hodgson TA, Cohen AJ. Medical expenditures for major diseases, 1995. Health Care Financ Rev. 1999;21(2):119-164.

9. Burns ER, Stevens JA, Lee R. The direct costs of fatal and non-fatal falls among older adults - United States. $J$ Safety Res. 2016;58:99-103. doi:10.1016/j.jsr.2016.05.001

10. Finkelstein EA, Chen H, Prabhu M, Trogdon JG, Corso PS. The relationship between obesity and injuries among US adults. $\mathrm{Am}$ $J$ Health Promot. 2007;21(5):460-468. doi:10.4278/0890-117121.5.460

11. Stolee P, Poss J, Cook RJ, Byrne K, Hirdes JP. Risk factors for hip fracture in older home care clients. J Gerontol A Biol Sci Med Sci. 2009;64(3):403-410. doi:10.1093/gerona/gln035

12. Guse CE, Porinsky R. Risk factors associated with hospitalization for unintentional falls: Wisconsin hospital discharge data for patients aged 65 and over. WMJ. 2003;102(4):37-42.

13. Grundstrom AC, Guse CE, Layde PM. Risk factors for falls and fall-related injuries in adults 85 years of age and older. Arch Gerontol Geriatr. 2012;54(3):421-428. doi:10.1016/j.archger.2011.06.008

14. Stone KL, Ensrud KE, Ancoli-Israel S. Sleep, insomnia and falls in elderly patients. Sleep Med. 2008;9(Suppl 1):S18-S22. doi:10.1016/ S1389-9457(08)70012-1

15. Avidan AY, Fries BE, James ML, Szafara KL, Wright GT, Chervin RD. Insomnia and hypnotic use, recorded in the minimum data set, as predictors of falls and hip fractures in Michigan nursing homes. J Am Geriatr Soc. 2005;53(6):955-962. doi:10.1111/j.15325415.2005.53304.x

16. Stone KL, Ancoli-Israel S, Blackwell T, et al. Actigraphy-measured sleep characteristics and risk of falls in older women. Arch Intern Med. 2008;168(16):1768-1775. doi:10.1001/archinte.168.16.1768

17. Chen YY, Wu KC. Sleep habits and excessive daytime sleepiness correlate with injury risks in the general population in Taiwan. Inj Prev. 2010;16(3):172-177. doi:10.1136/ip.2009.021840

18. Choi SW, Peek-Asa C, Sprince NL, et al. Sleep quantity and quality as a predictor of injuries in a rural population. Am J Emerg Med. 2006;24(2):189-196. doi:10.1016/j.ajem.2005.09.002

19. St George RJ, Delbaere K, Williams P, Lord SR. Sleep quality and falls in older people living in self- and assisted-care villages. Gerontology. 2009;55(2):162-168. doi:10.1159/000146786
20. Milewski MD, Skaggs DL, Bishop GA, et al. Chronic lack of sleep is associated with increased sports injuries in adolescent athletes. J Pediatr Orthoped. 2014;34(2):129-133. doi:10.1097/BPO.0000000 000000151

21. Kim SY, Sim S, Kim SG, Choi HG. Sleep deprivation is associated with bicycle accidents and slip and fall injuries in Korean adolescents. PLoS One. 2015;10(8):e0135753. doi:10.1371/journal. pone. 0135753

22. Chung JH, Kim JB, Kim JH. Effects of sleep duration and weekend catch-up sleep on falling injury in adolescents: a population-based study. Sleep Med. 2020;68:138-145. doi:10.1016/j.sleep.2019.12.005

23. Blatter K, Opwis K, Munch M, Wirz-Justice A, Cajochen C. Sleep loss-related decrements in planning performance in healthy elderly depend on task difficulty. J Sleep Res. 2005;14(4):409-417. doi:10.1111/j.1365-2869.2005.00484.x

24. Goel N, Rao H, Durmer JS, Dinges DF. Neurocognitive consequences of sleep deprivation. Semin Neurol. 2009;29(4):320-339. doi:10.1055/s-0029-1237117

25. Banks S, Dinges DF. Behavioral and physiological consequences of sleep restriction. J Clin Sleep Med. 2007;3(5):519-528. doi:10.5664/ jcsm. 26918

26. Ancoli-Israel S, Ayalon L, Salzman C. Sleep in the elderly: normal variations and common sleep disorders. Harv Rev Psychiatry. 2008;16(5):279-286. doi:10.1080/10673220802432210

27. Hayley AC, Williams LJ, Kennedy GA, et al. Excessive daytime sleepiness and falls among older men and women: cross-sectional examination of a population-based sample. Bmc Geriatr. 2015;15:74. doi:10.1186/s12877-015-0068-2

28. Krystal AD, Edinger JD. Measuring sleep quality. Sleep Med. 2008;9 (Suppl 1):S10-17. doi:10.1016/S1389-9457(08)70011-X

29. Harvey AG, Stinson K, Whitaker KL, Moskovitz D, Virk H. The subjective meaning of sleep quality: a comparison of individuals with and without insomnia. Sleep. 2008;31(3):383-393. doi:10.1093/sleep/ 31.3.383

30. Ohayon M, Wickwire EM, Hirshkowitz M, et al. National Sleep Foundation's sleep quality recommendations: first report. Sleep Health. 2017;3(1):6-19. doi:10.1016/j.sleh.2016.11.006

31. Buysse DJ, Reynolds CF, Monk TH, Berman SR, Kupfer DJ. The Pittsburgh Sleep Quality Index: a new instrument for psychiatric practice and research. Psychiatry Res. 1989;28(2):193-213. doi:10.1016/0165-1781(89)90047-4

32. Mollayeva T, Thurairajah P, Burton K, Mollayeva S, Shapiro CM, Colantonio A. The Pittsburgh sleep quality index as a screening tool for sleep dysfunction in clinical and non-clinical samples: a systematic review and meta-analysis. Sleep Med Rev. 2016;25:52-73. doi:10.1016/j.smrv.2015.01.009

33. Essien SK, Feng CX, Sun W, Farag M, Li L, Gao Y. Sleep duration and sleep disturbances in association with falls among the middle-aged and older adults in China: a population-based nationwide study. Bmc Geriatr. 2018;18(1):196. doi:10.1186/s12877-0180889-x

34. Kang YW, Ko YS, Kim YJ, et al. Korea community health survey data profiles. Osong Public Health Res Perspect. 2015;6(3):211-217. doi:10.1016/j.phrp.2015.05.003

35. Rim H, Kim H, Lee K, et al. Validity of self-reported healthcare utilization data in the Community Health Survey in Korea. $J$ Korean Med Sci. 2011;26(11):1409-1414. doi:10.3346/jkms.2011.26.11.1409

36. Sohn SI, Kim DH, Lee MY, Cho YW. The reliability and validity of the Korean version of the Pittsburgh Sleep Quality Index. Sleep Breath. 2012;16(3):803-812. doi:10.1007/s11325-011-0579-9

37. Choi H, Kim S, Kim B, Kim I. Psychometric properties of the Korean versions of three sleep evaluation questionnaires. Clin Nurs Res. 2015;24(5):526-538. doi:10.1177/1054773814549827 
38. Lee SY, Ju YJ, Lee JE, et al. Factors associated with poor sleep quality in the Korean general population: providing information from the Korean version of the Pittsburgh Sleep Quality Index. $J$ Affect Disord. 2020;271:49-58. doi:10.1016/j.jad.2020.03.069

39. Kim T, Choi SD, Xiong S. Epidemiology of fall and its socioeconomic risk factors in community-dwelling Korean elderly. PLoS One. 2020;15(6):e0234787. doi:10.1371/journal.pone.0234787

40. Deandrea S, Lucenteforte E, Bravi F, Foschi R, La Vecchia C, Negri E. Risk factors for falls in community-dwelling older people: a systematic review and meta-analysis. Epidemiology. 2010;21 (5):658-668. doi:10.1097/EDE.0b013e3181e89905

41. Choi EJ, Kim SA, Kim NR, Rhee JA, Yun YW, Shin MH. Risk factors for falls in older Korean adults: the 2011 Community Health Survey. J Korean Med Sci. 2014;29(11):1482-1487. doi:10.3346/ jkms.2014.29.11.1482

42. Franse CB, Rietjens JA, Burdorf A, et al. A prospective study on the variation in falling and fall risk among community-dwelling older citizens in 12 European countries. BMJ Open. 2017;7(6):e015827. doi:10.1136/bmjopen-2017-015827

43. Coups EJ, Ostroff JS. A population-based estimate of the prevalence of behavioral risk factors among adult cancer survivors and noncancer controls. Prev Med. 2005;40(6):702-711. doi:10.1016/j. ypmed.2004.09.011

44. Haskell WL, Lee IM, Pate RR, et al. Physical activity and public health: updated recommendation for adults from the American College of Sports Medicine and the American Heart Association. Circulation. 2007;116(9):1081-1093.

45. Deandrea S, Bravi F, Turati F, Lucenteforte E, La Vecchia C, Negri E. Risk factors for falls in older people in nursing homes and hospitals. A systematic review and meta-analysis. Arch Gerontol Geriatr. 2013;56(3):407-415. doi:10.1016/j.archger.2012.12.006

46. Tsai YJ, Yang PY, Yang YC, Lin MR, Wang YW. Prevalence and risk factors of falls among community-dwelling older people: results from three consecutive waves of the national health interview survey in Taiwan. Bmc Geriatr. 2020;20(1):529. doi:10.1186/s12877-02001922-z

47. Taylor CA, Bouldin ED, McGuire LC. Subjective cognitive decline among adults aged $\geq 45$ years - United States, 2015-2016. Morb Mortal Wkly Rep. 2018;67(27):753-757. doi:10.15585/mmwr. mm6727a1

48. Kroenke K, Spitzer RL, Williams JB. The PHQ-9: validity of a brief depression severity measure. J Gen Intern Med. 2001;16(9):606-613. doi:10.1046/j.1525-1497.2001.016009606.x

49. Han C, Jo SA, Kwak JH, et al. Validation of the Patient Health Questionnaire-9 Korean version in the elderly population: the Ansan Geriatric study. Compr Psychiatry. 2008;49(2):218-223. doi:10.1016/j.comppsych.2007.08.006

50. Brassington GS, King AC, Bliwise DL. Sleep problems as a risk factor for falls in a sample of community-dwelling adults aged 64-99 years. J Am Geriatr Soc. 2000;48(10):1234-1240. doi:10.1111/ j.1532-5415.2000.tb02596.x

51. Latimer Hill E, Cumming RG, Lewis R, Carrington $\mathrm{S}$, Le Couteur DG. Sleep disturbances and falls in older people. J Gerontol A Biol Sci Med Sci. 2007;62(1):62-66. doi:10.1093/gerona/62.1.62

52. Wu L, Sun D. Sleep duration and falls: a systemic review and meta-analysis of observational studies. J Sleep Res. 2017;26 (3):293-301. doi:10.1111/jsr.12505

53. Stone KL, Blackwell TL, Ancoli-Israel S, et al. Sleep disturbances and risk of falls in older community-dwelling men: the outcomes of Sleep Disorders in Older Men (MrOS Sleep) Study. $J$ Am Geriatr Soc. 2014;62(2):299-305. doi:10.1111/jgs.12649

54. Fallone G, Owens JA, Deane J. Sleepiness in children and adolescents: clinical implications. Sleep Med Rev. 2002;6(4):287-306.
55. Hsu CL, Nagamatsu LS, Davis JC, Liu-Ambrose T. Examining the relationship between specific cognitive processes and falls risk in older adults: a systematic review. Osteoporosis Int. 2012;23 (10):2409-2424. doi:10.1007/s00198-012-1992-z

56. Mirelman A, Herman T, Brozgol M, et al. Executive function and falls in older adults: new findings from a five-year prospective study link fall risk to cognition. PLoS One. 2012;7(6):e40297. doi:10.1371/ journal.pone.0040297

57. Schlesinger A, Redfern MS, Dahl RE, Jennings JR. Postural control, attention and sleep deprivation. Neuroreport. 1998;9(1):49-52. doi:10.1097/00001756-199801050-00010

58. Goldman SE, Stone KL, Ancoli-Israel S, et al. Poor sleep is associated with poorer physical performance and greater functional limitations in older women. Sleep. 2007;30(10):1317-1324. doi:10.1093/ sleep/30.10.1317

59. Dam TTL, Ewing S, Ancoli-Israel S, et al. Association between sleep and physical function in older men: the osteoporotic fractures in men sleep study. J Am Geriatr Soc. 2008;56(9):1665-1673. doi:10.1111/ j.1532-5415.2008.01846.x

60. Eshkoor SA, Hamid TA, Nudin SS, Mun CY. The effects of sleep quality, physical activity, and environmental quality on the risk of falls in dementia. Am J Alzheimers Dis Other Demen. 2013;28 (4):403-407. doi:10.1177/1533317513488921

61. Piovezan RD, Abucham J, Dos Santos RV, Mello MT, Tufik S, Poyares D. The impact of sleep on age-related sarcopenia: possible connections and clinical implications. Ageing Res Rev. 2015;23(Pt B):210-220.

62. Zhang X, Huang P, Dou Q, et al. Falls among older adults with sarcopenia dwelling in nursing home or community: a meta-analysis. Clin Nutr. 2020;39(1):33-39. doi:10.1016/j. clnu.2019.01.002

63. Veronese N, Smith L, Barbagallo M, et al. Sarcopenia and fall-related injury among older adults in five low- and middle-income countries. Exp Gerontol. 2021;147:111262.

64. Cappuccio FP, Cooper D, D’Elia L, Strazzullo P, Miller MA. Sleep duration predicts cardiovascular outcomes: a systematic review and meta-analysis of prospective studies. Eur Heart J. 2011;32 (12):1484-1492. doi:10.1093/eurheartj/ehr007

65. Kanda A, Matsui T, Ebihara S, Arai H, Sasaki H. Periventricular white matter lesions and sleep alteration in older people. $J \mathrm{Am}$ Geriatr Soc. 2003;51(3):432-433. doi:10.1046/j.15325415.2003.51125.x

66. Del Brutto OH, Mera RM, Zambrano M, Lama J, Del Brutto VJ, Castillo PR. Poor sleep quality and silent markers of cerebral small vessel disease: a population-based study in community-dwelling older adults (The Atahualpa Project). Sleep Med. 2015;16 (3):428-431. doi:10.1016/j.sleep.2014.10.023

67. Srikanth V, Beare R, Blizzard L, et al. Cerebral white matter lesions, gait, and the risk of incident falls: a prospective population-based study. Stroke. 2009;40(1):175-180. doi:10.1161/STROKEAHA.108.524355

68. Shearer WT, Reuben JM, Mullington JM, et al. Soluble TNF- $\alpha$ receptor 1 and IL-6 plasma levels in humans subjected to the sleep deprivation model of spaceflight. J Allergy Clin Immunol. 2001;107 (1):165-170. doi:10.1067/mai.2001.112270

69. Patel SR, Zhu X, Storfer-Isser A, et al. Sleep duration and biomarkers of inflammation. Sleep. 2009;32(2):200-204. doi:10.1093/sleep/ 32.2.200

70. Visser M, Pahor M, Taaffe DR, et al. Relationship of interleukin-6 and tumor necrosis factor-alpha with muscle mass and muscle strength in elderly men and women: the Health ABC Study. $J$ Gerontol A Biol Sci Med Sci. 2002;57(5):M326-M332. doi:10.1093/gerona/57.5.M326

71. Kuo HK, Bean JF, Yen CJ, Leveille SG. Linking C-reactive protein to late-life disability in the National Health and Nutrition Examination Survey (NHANES) 1999-2002. J Gerontol A Biol Sci Med Sci. 2006;61(4):380-387. doi:10.1093/gerona/61.4.380 
72. Buysse DJ, Hall ML, Strollo PJ, et al. Relationships between the Pittsburgh Sleep Quality Index (PSQI), Epworth Sleepiness Scale (ESS), and clinical/polysomnographic measures in a community sample. J Clin Sleep Med. 2008;4(6):563-571. doi:10.5664/jcsm.27351

73. Backhaus J, Junghanns K, Broocks A, Riemann D, Hohagen F. Testretest reliability and validity of the Pittsburgh Sleep Quality Index in primary insomnia. $J$ Psychosom Res. 2002;53(3):737-740. doi:10.1016/S0022-3999(02)00330-6

74. Grandner MA, Kripke DF, Yoon IY, Youngstedt SD. Criterion validity of the Pittsburgh Sleep Quality Index: investigation in a non-clinical sample. Sleep Biol Rhythms. 2006;4(2):129-139. doi:10.1111/j.1479-8425.2006.00207.x

75. Carpenter JS, Andrykowski MA. Psychometric evaluation of the Pittsburgh Sleep Quality Index. J Psychosom Res. 1998;45(1):5-13. doi:10.1016/S0022-3999(97)00298-5

76. Alsaadi SM, McAuley JH, Hush JM, et al. Detecting insomnia in patients with low back pain: accuracy of four self-report sleep measures. BMC Musculoskelet Disord. 2013;14:196. doi:10.1186/ 1471-2474-14-196
77. Pilz LK, Keller LK, Lenssen D, Roenneberg T. Time to rethink sleep quality: PSQI scores reflect sleep quality on workdays. Sleep. 2018;41(5). doi:10.1093/sleep/zsy029

78. Zia A, Kamaruzzaman SB, Tan MP. The consumption of two or more fall risk-increasing drugs rather than polypharmacy is associated with falls. Geriatr Gerontol Int. 2017;17(3):463-470. doi:10.1111/ggi.12741

79. Ie K, Chou E, Boyce RD, Albert SM. Fall risk-increasing drugs, polypharmacy, and falls among low-income community-dwelling older adults. Innov Aging. 2021;5(1):igab001. doi:10.1093/geroni/igab001

80. Fried TR, O'Leary J, Towle V, Goldstein MK, Trentalange M, Martin DK. Health outcomes associated with polypharmacy in community-dwelling older adults: a systematic review. $\mathrm{J} \mathrm{Am}$ Geriatr Soc. 2014;62(12):2261-2272. doi:10.1111/jgs.13153
International Journal of General Medicine

\section{Publish your work in this journal}

The International Journal of General Medicine is an international, peer-reviewed open-access journal that focuses on general and internal medicine, pathogenesis, epidemiology, diagnosis, monitoring and treatment protocols. The journal is characterized by the rapid reporting of reviews, original research and clinical studies
Dovepress

across all disease areas. The manuscript management system is completely online and includes a very quick and fair peer-review system, which is all easy to use. Visit http://www.dovepress.com/ testimonials.php to read real quotes from published authors. 